\title{
Trimethoprim-sulphamethoxazole in the treatment of persistent diarrhoea: a double blind placebo controlled clinical trial
}

\author{
N H Alam, P K Bardhan, R Haider, D Mahalanabis
}

\begin{abstract}
The efficacy of an absorbable antimicrobial agent trimethoprim-sulphamethoxazole (TMP-SMX) in the management of children with persistent diarrhoea was evaluated in a double blind, randomised, and placebo controlled trial. Of the 55 patients studied, 28 received TMP-SMX, and 27 received placebo. A trend in stool weight reduction was observed from the third day after the drug was started, and the reduction was statistically significant on day 6 and day 7. However, the difference in total stool output ( $\mathrm{g} / \mathrm{kg}$ ) up to day 7 was not significantly different between the two groups. The proportion of children whose diarrhoea resolved by day 7 (therapeutic success) was significantly more in the treatment group compared with the placebo group (23 v 15). Additionally, mean duration of diarrhoea in the group that received TMP-SMX was less compared with the placebo group (6.0 $v$ 8.3 days); this difference, however, was not significant. Hospital infection (probably nosocomial infection) was significantly less in the TMP-SMX treated group (1 $v$ 10). The results of our study indicate that TMP-SMX has a clinical benefit in respect of reducing the stool output, and higher recovery rate within seven days of treatment. In addition, it prevented possible hospital acquired infection.

(Arch Dis Child 1995; 72: 483-486)
\end{abstract}

Keywords: trimethoprim-sulphamethoxazole, persistent diarrhoea, randomised controlled trials.

Persistent diarrhoea is one of the common clinical problems seen in developing countries. One of the mechanisms suggested in the pathogenesis of persistent diarrhoea is small bowel bacterial overgrowth. ${ }^{1-3}$ Treatment of persistent diarrhoea is still based on dietary management, fluid treatment, and general supportive measures. Clinical experiences of the use of antibacterials and antidiarrhoeal agents are limited. A combination of oral gentamicin, metronidazole, and cholestyramine was found to be effective in terminating diarrhoeal illness in most treated patients in an early report. ${ }^{4}$ The study, however, lacked a control group. Another study evaluated the efficacy of oral gentamicin, metronidazole, and cholestyramine in persistent diarrhoea in a controlled trial ${ }^{5}$; gentamicin resulted in a significant decrease in stool weight. Tropical sprue, a syndrome of chronic diarrhoea associated with malabsorption in adults and older children is widely prevalent in this subcontinent and often responds to a course of tetracycline. Trimethoprim-sulphamethoxazole (TMPSMX) is a widely used antimicrobial having very good activity against many Gram negative bacteria.

The present study was carried out to evaluate the efficacy of TMP-SMX in the treatment of children suffering from persistent diarrhoea.

\section{Methods}

PATIENT SELECTION

The study was conducted at the Clinical Research and Service Centre of the International Centre for Diarrhoeal Disease Research, Bangladesh (ICDDR,B). The protocol was approved by the research review and ethics review committees of the centre. Patients eligible for the study were children of 5 months to 15 months of age with a history of diarrhoea acute in onset and persisting for more than 14 days but less than six weeks, and who had: (1) at least four liquid stools over 24 hours before admission, (2) stool output more than $50 \mathrm{~g} / \mathrm{kg}$ body weight in 24 hours during the observation period, (3) no systemic infection requiring antibacterial treatment (for example, pneumonia, meningitis, and septicaemia, etc), (4) no severe malnutrition (for example, marasmus or kwashiorkor), (5) no history of antibacterial drugs at least seven days before admission, (6) no sulphonamide or co-trimoxazole hypersensitivity, (7) initial stool culture negative for Vibrio cholerae, salmonella, shigella, and microscopic stool examination negative for Entamoeba histolytica/Giardia lamblia during the observation period. Consent was obtained from the parent(s) or legal guardian before the patient entered into the study.

Patients were hospitalised in the clinical research unit of the centre throughout the study period. Initial evaluation included a standard clinical history, physical examination including anthropometry, and stool output measurements for 48 hours on hospital standard diet (milk-rice cereal, oil mixture). ${ }^{6}$ During this initial 48 hours (observation period) some laboratory investigations were also carried out. These included microscopic stool examination for pus cells, parasites (including $G$ lamblia, $E$ histolytica, and cryptosporidium), stool culture for shigella, salmonella, $V$ cholerae, Campylobacter jejuni, and diarrhoeagenic Escherichia coli, and enzyme 
Table 1 Baseline clinical characteristics of patients; values are mean (SD) or number

\begin{tabular}{lcc}
\hline & $\begin{array}{c}\text { TMP_SPX group } \\
(n=28)\end{array}$ & $\begin{array}{c}\text { Placebo group } \\
(n=27)\end{array}$ \\
\hline Age (months) & $9 \cdot 0(2 \cdot 5)$ & $8 \cdot 5(2 \cdot 3)$ \\
Male/female & $20 / 8$ & $19 / 8$ \\
Body weight on admission $(\mathrm{kg})$ & $6 \cdot 6(1 \cdot 0)$ & $6 \cdot 4(0 \cdot 9)$ \\
Duration of diarrhoea before admission (days) & $21 \cdot 6(7 \cdot 2)$ & $21 \cdot 2(7 \cdot 8)$ \\
No of stools 24 hours before admission & $13 \cdot 6(8 \cdot 5)$ & $10 \cdot 6(4 \cdot 6)$ \\
Stool output in first 24 hours ${ }^{\star}(\mathrm{g} / \mathrm{kg})$ & $123 \cdot 0(42 \cdot 1)$ & $126 \cdot 4(48 \cdot 2)$ \\
No of vomits 24 hours before admission & $2 \cdot 9(4 \cdot 8)$ & $2 \cdot 6(2 \cdot 6)$ \\
No breast feeding on admission & 27 & 27 \\
Stool pathogens & 6 & 8 \\
$\quad$ Rotavirus & 5 & 7 \\
Enterotoxigenic $E$ coli & 4 & 7 \\
Enteroadherent $E$ coli & & \\
\hline
\end{tabular}

$\star$ Observation period.

\section{Drug treatment}

In children receiving TMP-SMX, the dose was adjusted to give $10 \mathrm{mg}$ of trimethoprim $/ \mathrm{kg}$ of body weight per day divided into two 12 hourly doses for seven days. The medicine contained a mixture of sulphamethoxazole and trimethoprim in a conventional ratio of 5:1. The patients were treated in the hospital with close monitoring until the diarrhoea had stopped and remained under observation in the hospital for at least two diarrhoea free days. Body weight, intake of intravenous/oral rehydration fluid, water and diet, and output of stool, vomit, and urine were measured every eight hours, and clinical evaluation reports were recorded every morning and afternoon. Cessation of diarrhoea was defined as the appearance of soft or formed stool and no diarrhoea (liquid stool) for 48 hours. Liquid stool can be poured from one container to another, soft stool takes the shape of the container, and the formed stool retains its shape. Therapeutic success was defined as the cessation of diarrhoea within seven days of starting the TMP-SMX or placebo treatment. Hospital infection was identified as isolation of diarrhoeagenic pathogen on subsequent stool culture after the drug was started and continuation of diarrhoeal symptom, and/or signs of other infection (for example, fever, cough, toxicity, crackles on auscultation of chest, etc) that required antibacterial treatment. arranged and numbered sequentially to correspond to patients' serial numbers and the randomisation code. TMP-SMX and placebo were supplied and randomised by the World Health Organisation, Geneva. The randomisation code was kept sealed until data were fully computerised and provided to the centre's administration. For analysis the code in the form of group A and B, without disclosing their identity, was provided to the investigators. On submission of the data analysis tables the group identity was provided to the investigators for preparing the final report.

\section{CASE MANAGEMENT}

Fluid treatment

The fluid balance in patients was maintained using either intravenous fluids containing sodium $133 \mathrm{mmol} / \mathrm{l}$, chloride $98 \mathrm{mmol} / 1$, potassium $13 \mathrm{mmol} / \mathrm{l}$, and acetate equivalent bicarbonate of $48 \mathrm{mmol} / \mathrm{l}$, or oral rehydration solution. The patients with high purging rate (stool output $>100 \mathrm{~g} / \mathrm{kg} /$ day) were given only intravenous fluid for maintaining hydration.

\section{Diet}

Initial diet after admission into the study (that is on commencement of medicine intake) was based on rice, glucose, egg albumin, vegetable oil and salts mixture, which is routinely used for persistent diarrhoea patients at ICDDR,B. ${ }^{8}$ This mixture has an energy density of $209 \mathrm{~kJ}$ (50 kcal)/100 g. Breast milk was allowed ad libitum. The patients, in addition, received multivitamin drops 10 drops twice daily plus zinc acetate $5 \mathrm{mg}$ three times daily orally as per hospital practice.

\section{DATA ANALYSIS}

All data were computerised using StatPack Gold software package (Walonick Associates) in a microcomputer. Data analyses were done using a data analysis package (SPSS/PC+ Inc). Continuous variables were compared between the groups with Student's $t$ test; $\chi^{2}$ test was used for dichotomous variables. A non-parametric test (Mann-Whitney U-Wilcoxon rank sum W) was also used to compare the skewed data. Survival analysis was also done for the duration of diarrhoea and compared between the groups with the log rank test.

\section{Results}

Of the 55 patients studied, 28 received TMPSMX and 27 received placebo. Baseline clinical characteristics of patients were comparable between the two groups (table 1). A trend in reduction of stool weight was observed from the third day after the drug was started,

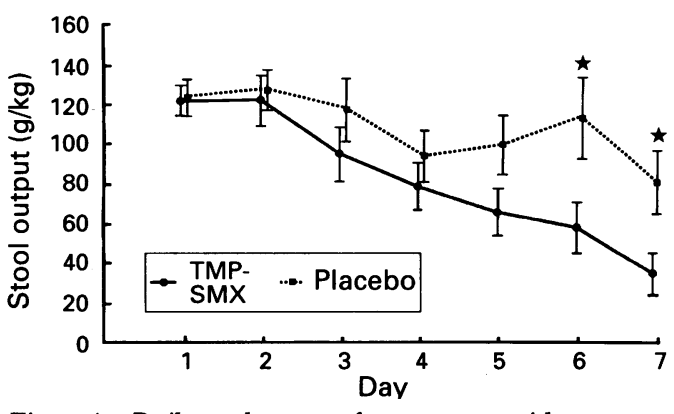

Figure 1 Daily stool output after treatment with TMP-SMX or placebo in patients with persistent diarrhoea; values are mean $(S E M) ; \star^{*}=0.02$. 
Table 2 Comparison of total stool output up to day 7, energy intake, duration of diarrhoea, outcome (success/failure), and hospital infection between two groups; values are mean $(S D)$ or number

\begin{tabular}{lll}
\hline & $\begin{array}{l}\text { TMP-SMX group } \\
(n=28)\end{array}$ & $\begin{array}{c}\text { Placebo group } \\
(n=27)\end{array}$ \\
\hline Total 7 day stool output (g/kg) & $577 \cdot 0(321 \cdot 5)$ & $756 \cdot 4(425 \cdot 1)$ \\
$\begin{array}{l}\text { Energy intake (kJ [kcal]/kg/day) from } \\
\text { hospital diet }\end{array}$ & $181(60)[43 \cdot 4(14 \cdot 3)]$ & $188(61)[44 \cdot 9(14 \cdot 6)]$ \\
Duration of diarrhoea (days) & $6 \cdot 0(4 \cdot 5)$ & $8 \cdot 3(5 \cdot 9)$ \\
Outcome (success/failure) & $23 / 5^{\star}$ & $15 / 12$ \\
Hospital infection & 1 & $10^{\star \star}$ \\
\hline
\end{tabular}

$\chi^{2}$ test: ${ }^{\star} \mathrm{p}=0.03 ;{ }^{\star \star} \mathrm{p}=0.003$ injection, three were given ampicillin injection, and one received oral erythromycin. No drug related untoward effect was observed in the study patients.

\section{Discussion}

The results of the present study suggested that TMP-SMX in the treatment of severe persistent diarrhoea has a clinical benefit in terms of reducing the stool weight, duration of diarrhoea, and providing a higher rate of recovery from diarrhoea within seven days of treatment. In addition, it prevented hospital acquired infections. The mechanism of this apparent clinical benefit can only be speculated. TMPSMX may have been effective in treating and preventing small bowel colonisation. A potential benefit of using antimicrobial agents in the treatment of persistent diarrhoea was suggested by two lines of evidence from study reports on persistent diarrhoea: (a) association of persistent episodes with small bowel bacterial overgrowth, principally with Gram negative enteric bacteria ${ }^{1-3}$ and (b) the frequent isolation in such episodes of various types of enteroadherent $E$ coli. ${ }^{9-11}$ A few reports have shown advantages in terminating diarrhoeal episodes with oral gentamicin, ${ }^{45}$ an unabsorbable broad spectrum antimicrobial, although one community based study failed to show this clinical benefit. ${ }^{12}$ The advantages of an absorbable oral antimicrobial is that besides its activity against gut infection, it might control other infections (for example, respiratory tract infection, urinary tract infection, etc). TMP-SMX is a widely used antimicrobial active against many Gram positive and Gram negative bacteria and might have been involved in preventing hospital infections in our patients. This could be an alternative or additional mechanism through which the patients receiving TMP-SMX have shown a clinical benefit.

The results of our study indicate that TMPSMX was effective in reducing the stool output, duration of diarrhoea, and there was a higher recovery rate within seven days of treatment. In addition, it prevented possible hospital acquired infections. Further studies, both in hospitals and communities, are needed to support the recommendation of TMP-SMX in the treatment of persistent diarrhoea in children.

This study/publication was funded by the United States Agency for International Development under grant No DPE-5986-A1009-00 with the International Centre for Diarrhoeal Disease Research, Bangladesh (ICDDR,B). The ICDDR,B is supported by the aid agencies of the Governments of Australia, Bangladesh, Belgium, Canada, China, Denmark, Germany, Japan, the Netherlands, Norway, Republic of Korea, Saudi Arabia Sweden, Switzerland, the United Kingdom, and the United Swes; international organisations including, and the Gulf Fund Asian Devepment Bank, International Arab Gulf Fund, Asian Development Bank, International Atomic Energy Centre, the United Nations Children's Fund (UNICEF), the United Nations Development Programme (UNDP), the United Nations Population Fund (UNFPA), and the World Health Organisation; private foundations including the Ford Foundation, Population Council, Rockefelle Foundation and the Sasakawa Foundation; and private organisations including American Express Bank, Bayer AG, CARE, Helen Keller International, the Johns Hopkins University, Swiss Red Cross, and the University of California Davis

We would like to thank the World Health Organisation, Geneva for supplying us with the drug and the placebo. Thank are due to Mr M A Rahman Patwary for secretarial assistance.

Figure 2 Survival plot for duration of diarrhoea after treatment with TMP-SMX or placebo in patients with persistent diarrhoea. 
1 Penny ME, de Silva DGH, McNeish AS. Bacterial contamination of the small intestine of infants with enteropathoin the aetiology of persistent diarrhoea? BMF 1986; 292: in the aetio.

2 Hill ID, Mann MD, Moore L, Bowie MD. Duodenal microflora in infants with acute and persistent diarrhoea.

3 Davidson GP, Robb TA, Kirubakaran CP. Bacterial contamination of the small intestine as an important cause of chronic diarrhea and abdominal pain: diagnosis by breath hydrogen test. Pediatrics 1984; 74: 229-35.

4 Hill ID, Mann MD, Bowie MD. Successful management of persistent diarrhoea in infants. S Afr Med $\mathcal{F}$ 1980; 58:
241-3.

5 Hill ID, Mann MD, Househam KC, Bowie MD. Use of oral gentamicin, metronidazole, and cholestyramine in the treatment of severe persistent diarrhea in infants. Pediatrics 1986; 77: 477-81.

6 Roy SK, Alam AN, Majid N, Khan AM, Hamadani J, Shome GP. Persistent diarrhoea: a preliminary report on clinical features and dietary therapy in Bangladeshi children. $₹$ Trop Pediatr 1989; 35: 55-9.
7 Faruque SM, Haider $\mathrm{K}$, Albert MJ, et al. A comparative study of specific gene probes and standard bioassays to dentify diarrhoeagenic Escherichia coli in paediatric patients with diarrhoea in Bangladesh. $f$ Med Microbiol 1992; 36: 37-40

8 Roy SK, Haider R, Akbar MS, Alam AN, Khatun M, Eeckels R. Persistent diarrhoea: clinical efficacy and nutrient absorption with a rice based diet. Arch Dis Child 1990; 65: 294-7.

9 Bhan MK, Bhandari N, Sazawal S, et al. Descriptive epidemiology of persistent diarrhoea among young children in rural northern India. Bull World Health Organ 1989; 67: 281-8.

10 Baqui AH. Epidemiology of persistent diarrhea in Bangladeshi children. Baltimore, MD: Johns Hopkins University, 1990. (Dissertation.)

11 Henry FJ, Udoy AS, Wanke CA, Aziz KMA Epidemiology of persistent diarrhea and etiologic agents in Mirzapur, Bangladesh. Acta Paediatr 1992; 81 (suppl 381): 27-31.

12 Bartlett AV, Torun B, Morales C, Cano F, Cruz JR. Oral gentamicin is not effective treatment for persistent diarrhea. Acta Paediatr 1992; 81 (suppl 381): 149-54. 